\title{
ESTRUTURAÇÃO DA CADEIA REVERSA DE CELULARES E OS CRITÉRIOS RELEVANTES NA COMERCIALIZAÇÃO PÓS-CONSUMO
}

\author{
Paula Horta Lemos \\ Mestranda em Engenharia de Produção - PPGEP-So \\ Universidade Federal de São Carlos \\ paula_lemos_3@hotmail.com \\ José Geraldo Vidal Vieira \\ Professor Associado do Departamento de Engenharia de Produção - DEP-So \\ Universidade Federal de São Carlos \\ jose-vidal@ufscar.br
}

\section{RESUMO}

Este estudo tem por objetivo mapear a cadeia reversa de resíduos de celulares, por meio da aplicação do modelo de Lambert e Cooper (2000). Uma análise multicritério também foi proposta para entender quais são os principais critérios utilizados na comercialização desses resíduos, sob o ponto de vista da empresa focal. Neste caso, foram utilizadas duas empresas. Os resultados mostraram que a empresa A se posiciona mais a jusante, com ligações gerenciáveis nos elos adjacentes e foco em economias de escala; enquanto a empresa B tem uma posição central, gerencia elos adjacentes e distantes, portanto tem uma visão mais estratégica em termos de relacionamento colaborativo e com foco na melhoria dos aspectos ambientais, como menor índice de poluição no transporte, menos gastos de energia e menor grau de intoxicação com produtos. Este trabalho pode ser utilizado pelos atores da cadeia reversa de eletrônicos como referência para melhorar o fluxo de materiais e informações e por tomadores de decisões como meio estruturado para tomar decisões a partir de suas preferências dentro do ambiente de negócios.

Palavras-chave: Análise de decisão multicritério; Cadeia de suprimentos; Celulares; Logística reversa.

\section{STRUCTURE OF CELLULAR ADVICES REVERSE CHAIN AND RELEVANT CRITERIA IN POST-CONSUMER TRADE}

\begin{abstract}
The objective of this study is to map out the reverse logistics chain of cellular waste by applying Lambert and Cooper's (2000) model. Multi-criteria analysis is proposed to select the main criteria used for the trade of these wastes from the point of view of the local firm. For this, we conducted a study in two companies. The results showed that company A is positioned downstream of the chain, with managed adjacent links and focuses on scale economies. Company B has a central position, a strategic vision in terms of collaborative relationships, adjacent controls, and distant links. Company B also focuses on improving the environmental aspects, such as better pollution index regarding transportation, lower energy costs and lower level of intoxication products. This work can be a guide to the players of the reverse electronics chain as a reference to improve the flow of materials and information, and decision makers as a structured way to make decisions based on their preferences within the business environment.
\end{abstract}

Key words: Cellular devices; Multi-criteria decision-making; Reverse logistics; Supply chain. 


\section{INTRODUÇÃO}

O lixo eletrônico tem contribuído para um crescente aumento dos danos à natureza devido à quantidade de resíduos descartada e ao ciclo de vida cada vez mais curto desses resíduos (Prahinski, \& Kocabasoglu, 2006; Demajorovic, Huertas, Boueres, da Silva, \& Sotano, 2012). De acordo com Mendonça (2013), a indústria eletrônica é uma das indústrias de maior crescimento no mundo, incluindo países do terceiro mundo da Ásia e da América Latina. O consumo de eletrônicos, principalmente de celulares, e a necessidade de informações em tempo real tem crescido substancialmente, isso faz com que novos produtos com tecnologias inovadoras, capazes de executar um maior número de tarefas com mais flexibilidade e rapidez, surjam em intervalos de tempo cada vez menores. Devido à tendência de aumento desses produtos e somando-se ao fato dos resíduos gerados serem prejudiciais à saúde humana e ao ambiente, o Brasil instituiu a Política Nacional de Resíduos Sólidos (Pnrs). Esta política, segundo Moraes, Rocha, Edwald, Pimentel e Silva (2012), visa o gerenciamento ambiental adequado dos resíduos sólidos, estabelece o compartilhamento de responsabilidades pelo ciclo de vida dos produtos não restringindo aos fabricantes, importadores, distribuidores, comerciantes, consumidores e titulares dos serviços de limpeza urbana e manejo.

A oportunidade de investigar uma maneira de estruturar a cadeia reversa desses resíduos e o relacionamento entre os atores é clara. É fato que essas políticas instigam pesquisas que fomentem decisões mais estruturadas no sentido de promover eficiência no canal de distribuição. Acosta, Wegner e Padula (2008) procuraram identificar como funciona o processo de logística reversa de produtos eletrônicos em uma empresa atacadista. O resultado obtido foi que as empresas utilizam um sistema de logística reversa de pósvenda parcial para produtos com defeitos de fábrica que são revalorizados por meio de remanufatura, reuso e venda de peças em mercados secundários. Araujo, Matsuoka, Ung, Hilsdorf e Sampaio (2013) também estudaram as atividades de logística reversa e descreveram o processo do maior varejista virtual do mercado brasileiro, além de mostrar sua evolução, analisar seu desempenho e identificar as principais deficiências como sendo o alto custo de transporte e armazenagem. Esses trabalhos convergem à necessidade de conscientização dos problemas ambientais causados pelo descarte desses resíduos eletrônicos, sendo a reciclagem uma alternativa para minimizar esses problemas ambientais e elevar o valor agregado do lixo eletrônico (Rogers \& Tibben-Lembke, 2001). No entanto, esses estudos não exploram de maneira estruturada quais são os atores e respectivos papéis que eles desempenham na cadeia reversa e tão pouco como se dá o relacionamento entre eles.

O objetivo desta pesquisa é mapear a cadeia reversa de resíduos de celulares. Para isto o modelo de cadeia de suprimento de Lambert e Cooper (2000) é aplicado como forma estruturada para classificar os participantes nas camadas dessa cadeia e entender como se dão as relações entre as camadas antes e após a empresa focal (ou seja, aquela que detêm mais informações sobre o gerenciamento desses resíduos no canal reverso). Dada a importância estratégica da empresa focal na cadeia (Lambert e Cooper, 2000), o estudo também propõe um modelo decisório que auxilie na tomada de decisão de comercialização dos resíduos de aparelhos celulares. Esta investigação é importante à medida que mostra quais aspectos as empresas dão maior valor no momento de descartar esses resíduos. O modelo considera duas empresas de armazenamento e triagem de resíduos de celulares, como empresas focais. Para a tomada de decisão são considerados três principais aspectos: estratégicos, econômicos e ambientais. Ramos, Gomes e Povoa (2014) desenvolveram um modelo para apoiar as decisões dos sistemas de logística reversa e consideraram os aspectos econômicos, ambientais e sociais. Na literatura, o componente econômico tem sido frequentemente usado, enquanto as preocupações ambientais têm surgido recentemente. O elemento social raramente é utilizado e não foi abordado neste estudo. O elemento estratégico faz parte da contribuição desta pesquisa na medida em que analisa os critérios "relacionamento com o cliente", "frequência de entrega", "volume de materiais" e "nível de serviço". Critérios esses fundamentais para a comercialização dos resíduos.

O artigo está estruturado em cinco seções. Na seção dois é discutida a estruturação da cadeia reversa de celulares. É apresentado o modelo de Lambert e Cooper e discutido o relacionamento de colaboração entre os atores de uma cadeia. A seção três apresenta a metodologia de pesquisa. A seção quatro mostra os resultados com base na estruturação da cadeia e no modelo de análise de decisão que inclui os principais fatores que interferem na comercialização dos resíduos de celulares. Na seção cinco são feitas as considerações finais. 


\section{FUNDAMENTAÇÃO TEÓRICA}

A fundamentação teórica abordará os temas de estruturação da cadeia reversa de celulares; o modelo de Lambert e Cooper (2000) e será discutido também o relacionamento de colaboração entre os atores da cadeia.

\subsection{Estruturação da cadeia reversa de celulares: desafios emergentes}

É fato que o ciclo de vida dos celulares é curto, já que cada vez mais novas versões são lançadas e despertam o desejo de consumo dos usuários. De acordo com a Associação Brasileira da Indústria Eletroeletrônica (Abinee, 2015), as vendas de aparelhos celulares passaram de 27 milhões em 2003, para 63 milhões em 2015, ou seja, houve um aumento de 133,3\%. Devido a esse curto ciclo de vida dos aparelhos celulares, o descarte desse tipo de resíduo tem crescido demasiadamente. Estima-se que a cada ano em todo mundo sejam geradas 40 milhões de toneladas de lixo tecnológico (El Faro, Calia \& Pavan, 2013). Dados da Organização das Nações Unidas (ONU) apontam o Brasil como a segunda colocação de maior gerador de lixo proveniente de celulares, 2,2 mil toneladas por ano, perdendo apenas para a China. Porém segundo estimativas, somente $1 \%$ destes resíduos possuem um destino ambientalmente correto em sua cadeia reversa (Sergi, 2014).

A Figura 1 mostra o modelo de Achillas et al. (2010) com detalhes sobre os processos e as diferentes práticas relacionadas aos REEE (Resíduos de Equipamentos Eletroeletrônicos) após o seu fim de vida útil, principalmente os aspectos relacionados ao fluxo posterior à utilização. Os autores também identificam as possibilidades de reuso e reciclagem como alternativas após o tratamento inicial dos Reee (atividades de classificação, testes de usabilidade, segregação dos materiais e trituração).

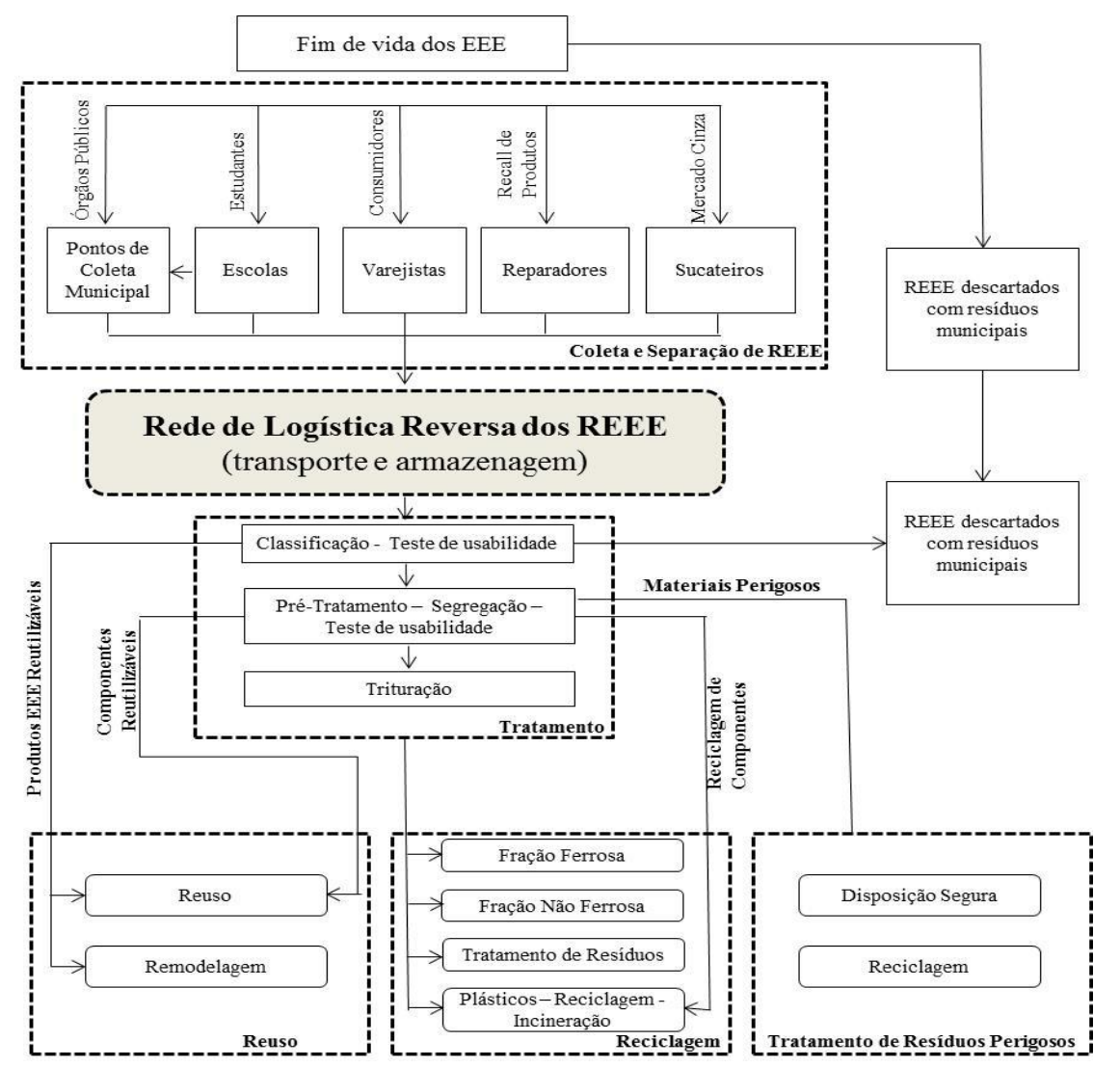

FIGURA 1 - Framework de Logística Reversa para REEE (Fonte: Achillas et al. (2010))

Embora Achillas et al. (2010) tenham proposto uma estrutura para representar a cadeia reversa, eles não procuraram identificar as ligações e o tipo de relacionamento entre esses elos. Prahinski, \& Kocabasoglu (2006) defendem que os principais conflitos tangem à falta de colaboração e à coordenação entre esses atores 
da cadeia produtiva sejam eles clientes, intermediários ou consumidores finais, que muitas vezes não colaboram adequadamente para o processo de retorno dos bens pós-consumo.

Dentre os problemas relacionados à cadeia reversa de eletrônicos, o processo de retorno dos aparelhos celulares pós-consumo pode ser considerado o mais crítico, visto que os consumidores finais muitas vezes não colaboram com o descarte correto destes resíduos (Novaes, 2001). Além disso, a coleta em si é um complicador, porque o "lixo eletrônico" está muito pulverizado por todo o país. Para mitigar estes problemas, a Pnrs obriga os fabricantes de telefones móveis a gerarem informações sobre seus produtos e que orientem os consumidores sobre os riscos socioambientais e de como proceder após o término do ciclo de vida útil dos produtos (Besen, Günther, Rodriguez, \& Brasil, 2010). Além desta política e outras exigências fiscais, de acordo com Jayant, Gupta, Garg e Khan (2014), os próprios consumidores têm pressionado as empresas a assumir a responsabilidade pelo descarte de seus produtos que contêm resíduos perigosos.

Algumas dificuldades com a coleta de resíduos eletrônicos dizem respeito à separação e à contaminação por materiais químicos prejudiciais à saúde. Além disso, a presença de atravessadores, os chamados "sucateiros", dificulta a melhoria da qualidade do processo, quer seja na qualidade e confiabilidade de entrega da coleta, quer seja pela precarização da força de trabalho envolvida. Somam-se a isso as poucas iniciativas de coleta seletiva, em comparação com a quantidade de lixo urbano produzida no país. Desta forma, é necessário maior investimento em informação e tecnologia. Levar ao grande público o conhecimento sobre a reciclagem e retorno dos materiais, instruindo sobre o correto descarte dos produtos também parece ser uma medida fundamental. Desenvolver tecnologias que permitam materiais mais fáceis de reciclar, inofensivos e inertes para proteção do meio ambiente é outra importante frente de ação (Dias \& Teodosio, 2006).

Já no âmbito da indústria de transformação, uma das dificuldades é a resistência quanto à utilização do material reciclado ou reutilizado, dificultando a compra dos resíduos para a produção de produtos de uso final (Dias \& Teodosio, 2006).

Ao mesmo tempo que os resíduos eletrônicos possuem consequências socioambientais devido às suas substâncias tóxicas, eles também podem gerar resultados econômicos, por conterem quantidades de materiais valiosos, que normalmente fornecem o incentivo monetário à reciclagem, pois incluem metais como cobre e metais preciosos como ouro, a prata e o paládio (Betts, 2008).

Reuso é o termo genérico para a recuperação do produto, mas muitas vezes também aponta para pouco ou nenhum reprocessamento (Mendonça, 2013). Em contraste com outros produtos eletrônicos, celulares têm um mercado de reutilização próspera. Segundo Geyer e Blass (2010) nos EUA, 65\% de todos os telefones celulares recolhidos são reutilizados em vez de reciclado. No Reino Unido esse número passa de $50 \%$. A maioria desses telefones reutilizados é vendida para desenvolver economias emergentes da África, Oriente Médio e Europa Oriental (Geyer \& Blass, 2010). Assim, segundo Fernando e Jorge (2015), na ausência de uma legislação forte, a rentabilidade é o principal motor da coleta e reprocessamento de resíduos de aparelhos eletrônicos. Avaliar os aspectos econômicos da reutilização de telefone celular e reciclagem é, portanto, essencial para compreender as atividades de gerenciamento destes resíduos. Esses aspectos econômicos desses resíduos estão relacionados aos altos custos de logística e reprocessamento, que envolvem as atividades de coleta, transporte, inspeção e triagem (Hori, 2010). Levando-se em conta as estimativas para o mercado americano e extrapolando-as para o Brasil, os custos com logística reversa representam aproximadamente $4 \%$ dos custos totais de logística. Estes números tendem a crescer, à medida que as atividades com Logística Reversa aumentem entre as empresas (Daher, Silva \& Fonseca, 2006). O pequeno número de sistemas informatizados na logística reversa que se integrem ao sistema existente de logística tradicional (Caldwell, 1999) e a dificuldade em medir o impacto dos retornos de produtos, recebem pouca ou nenhuma prioridade de estudo (Quinn, 2001). Dessa forma, apesar do crescimento da indústria de eletrônicos acontecer de maneira acelerada, pode-se perceber que esse crescimento ocorre de forma desorganizada. As indústrias de eletrônicos e até mesmo as empresas que realizam a reciclagem não possuem dados a respeito da quantidade de materiais retornados, o que impossibilita a verificação da porcentagem de reaproveitamento desses materiais, sua eficiência, custos correspondentes, entre outros aspectos importantes para a condução e gestão empresarial.

As duas principais fontes de receitas na cadeia reversa de celualres são: a venda de aparelhos remanufaturados para reutilização e a venda dos metais recuperados nos mercados de commodities (Fernando \& Jorge, 2015). Para Miguez (2010), as vendas de materiais secundários são a melhor fonte de receita de reciclagem de telefone. Cerca de $70 \%$ das receitas de reciclagem são do ouro contido em 
aparelhos, por outro lado, ao considerar a quantidade em massa de material reciclado, o cobre é o maior responsável.

\subsection{Modelo de Lambert e Cooper}

De acordo com Lambert e Cooper (2000), a implementação da cadeia é feita com base em três elementos, a estrutura da cadeia de suprimentos, os processos de negócios da cadeia e os componentes de gestão. Nesta pesquisa será abordada apenas a estrutura de rede (cadeia). A Figura 2 ilustra uma rede genérica, com a empresa foco e membros de primeira a terceira camadas de jusante a montante (fornecedores e clientes).

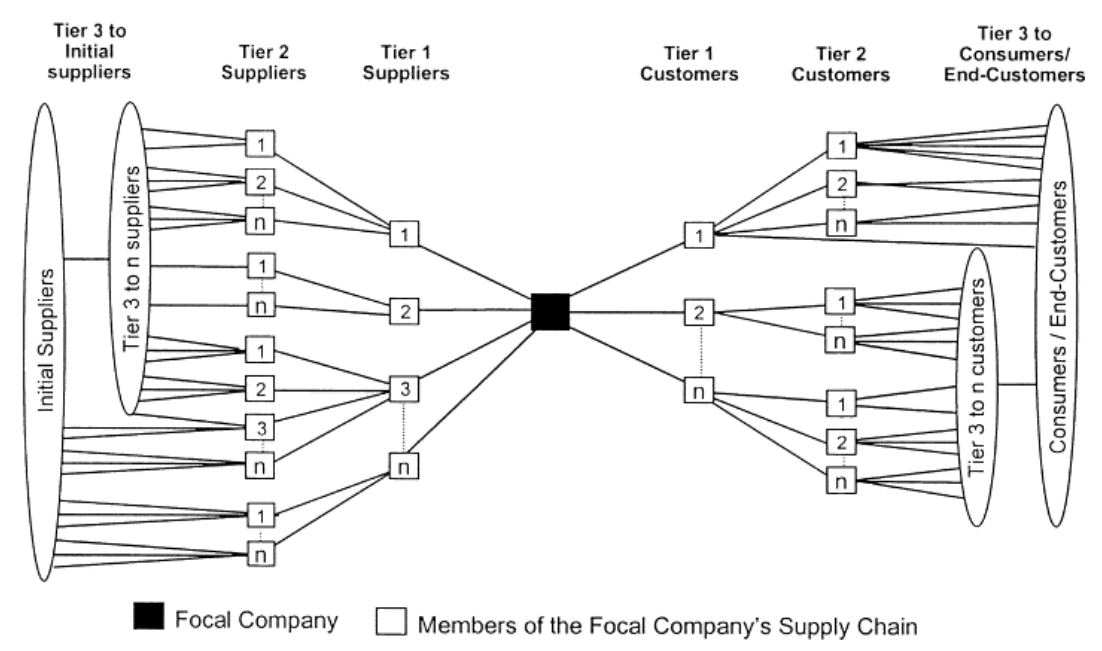

FIGURA 2: Estrutura da cadeia de suprimentos (Fonte: Lambert e Cooper, 2000).

Os membros dessa cadeia de suprimentos genérica são representados por empresas que de alguma maneira interagem com a empresa foco, seja por meio de uma integração logística com elos gerenciados ou através de transações não recorrentes (Vieira, Lustosa \& Yoshizaki, 2003). A empresa foco pode ser definida, segundo Novaes (2001), a partir de fatores como: ter o maior número de fornecedores ou clientes, agregar mais valor à rede, ser responsável por vários processos dentro da cadeia, deter de mais recursos financeiros, entre outros. Lambert e Cooper (2000) classificam esses membros entre primários e de apoio. Os primários são aqueles que desempenham atividades que agregam valor nos processos de transformação de insumos em produtos para o consumidor final e os membros de apoio são aqueles que oferecem recursos, conhecimentos, utilidades ou bens para os membros principais. As dimensões da cadeia podem ser dividas em horizontal e vertical. A dimensão horizontal é a quantidade de níveis no sentido horizontal, e pode ser curta ou longa. A dimensão vertical é a quantidade de níveis no sentido vertical, podendo ser uma cadeia larga ou estreita. Os tipos de ligações, segundo Lambert e Cooper (2000), podem ser classificados em gerenciadas, monitoradas, não gerenciadas e ligações com não membros da cadeia. As ligações de processos gerenciados são aquelas nas quais a companhia em foco dá importância ao ato de gerenciar. As ligações monitoradas são aquelas em que a companhia monitora a ligação a fim de saber como os processos estão integrados e gerenciados. As ligações de processos não gerenciados são as ligações com as quais a companhia em foco não está ativamente envolvida. As ligações de processos com "não membros" da cadeia acontecem com membros externos, porém podem afetar o desempenho da cadeia. Araujo, Matsuoka, Ung, Hilsdorf e Sampaio (2013) explica que o bom relacionamento pode contribuir para diminuir custos e propiciar vantagens competitivas através de eficientes trocas de informações entre os elos da cadeia, difusão do conhecimento e participação da comunidade acadêmica no desenvolvimento dos setores envolvidos.

\subsection{Colaboração na cadeia de suprimentos reversa}

O sucesso da integração de uma cadeia de suprimentos depende de laços de colaboração entre os parceiros que trabalham em conjunto para melhor gerenciar o uso de recursos em um ambiente de confiança 
mútua e de partilha de informações, riscos e recompensas para alcançar melhorias de desempenho (Ellram \& Cooper, 1990; Whipple, Frankel, \& Daugherty, 2002). Segundo Bowersox, Closs, Cooper e Bowersox (2013), a gestão da cadeia de suprimentos deve-se baseiar na colaboração entre empresas para impulsionar o posicionamento estratégico e melhorar a eficiência operacional. Uma estratégia na cadeia é um arranjo organizacional de canais e de negócios baseados na dependência e colaboração. As operações da cadeia de suprimentos exigem processos gerenciais que atravessam as áreas funcionais dentro de cada empresa e conectam fornecedores, parceiros comerciais e clientes através das fronteiras organizacionais (Flynn, Huo \& Zhao, 2010).

A integração externa entre compradores e fornecedores tem sido bem estudada em logística e literatura de gestão. Corsten e Felde (2005) afirmam a importância da gestão colaborativa do relacionamento com fornecedores-chaves na distribuição e gerenciamento logístico. El-Ansary (1992) enfatiza a importância do compartilhamento de informação entre parceiros: ambos têm interesses em atender às expectativas do consumidor de serviço e qualidade na entrega do produto. Heide e John (1990) destacam a importância das ações conjuntas e Ellram e Cooper (1990) sublinham a importância de confiança e compromisso para relacionamentos de longo prazo entre os atores. Barrat (2004) explica que os elementos culturais e estratégicos são a base de práticas colaborativas, tais como atividades multifuncionais, alinhamento de processos, tomada de decisão conjunta, e as métricas da cadeia de suprimentos.

No que tange à logística reversa, Rodrigues, Rodrigues, Leal e Pizzolato (2002) destacaram como uma das grandes dificuldades, as tensões entre varejistas e fabricantes, como, por exemplo, conflitos relacionados à interpretação de quem é a responsabilidade sobre os danos causados aos produtos, tais como no transporte e na fabricação. Além disso, a falta de coordenação e cooperação nos processos de coleta, manuseio, armazenagem, processamento e troca de materiais recicláveis, também são considerados como barreiras da logística reversa. Segundo Fleury e Fleury (2004), uma das características essenciais em uma cadeia reversa é a competência inter-organizacional de cada empresa da cadeia, pois esta competência pode influenciar nas estratégias competitivas da cadeia como um todo. Desse modo, a competitividade pede uma eficiência coletiva em que as empresas devem almejar por colaboração e troca de informações a fim de realizar seus objetivos. Porém, segundo Ruas, Antonello e Boff (2005), o conhecimento sistematizado, bem como o debate acerca da interação entre as competências das empresas que compõem a cadeia de suprimentos ainda é muito frágil no fluxo reverso.

Dessa forma, a importância no relacionamento, cooperação e colaboração entre parceiros tem sido discutida em alguns trabalhos como elementos essenciais para a operacionalização da logística reversa. Guarnieri (2011) afirma que um processo de logística reversa de pós-venda bem gerenciado propicia vantagem competitiva através da diferenciação no atendimento, que agrega valor perceptível aos clientes e, em longo prazo, os fideliza. Empresas líderes de mercado assumem tal papel e têm um relacionamento de parceria entre fornecedores e clientes, e assim, contribuem para a redução de impactos ambientais e constroem uma imagem positiva frente à sociedade. Como exemplo desse relacionamento de parceria entre fornecedores e clientes em serviços de logística reversa, pode-se citar a indústria automobilística que, ao detectar um defeito no automóvel que possa ocasionar algum risco ao usuário, convocam os clientes a comparecerem para sanar o problema. Para isso, deve ser planejada entre os parceiros a estrutura da logística reversa para operacionalizar o retorno das peças defeituosas.

Os ganhos com a cooperação também se observam nas indústrias de refrigerantes. Caldwell (1999) relata grandes economias incorridas por uma engarrafadora de Coca-Cola, no México, após a implementação de um sistema de gerenciamento da logística reversa com a participação diretamente dos participantes nos processo de retorno. Estes ganhos se deram desde uma melhor coordenação entre promoções e picos esperados no retorno de vasilhames que reduzem a necessidade de produção de novos vasilhames.

\section{MÉTODO DE PESQUISA}

A metodologia de pesquisa é composta por quatro passos: (1) revisão de literatura a respeito dos critérios; (2) levantamento de dados por meio de entrevistas e questionários para mapear o descarte de celulares; (3) utilização do modelo de Lamber e Cooper (2000) para mapear a cadeia; (4) modelo multicritério para estruturar a comercialização dos resíduos.

Ressalta-se que no passo 2, primeiramente, foram feitas entrevistas a 50 indivíduos, escolhidos aleatoriamente, a respeito do local de descarte do aparelho celular, com o objetivo de entender o descarte de aparelhos celulares para, então, iniciar a caracterização da cadeia reversa de celulares e localizar os principais pontos de descarte. Ainda, foram realizadas 27 entrevistas semiestruturadas os seguintes atores: 10

Revista de Gestão Social e Ambiental - RGSA, São Paulo, v. 10, n. 2, p. 53-69, maio/ago. 2016. 
lojas de telefonia celular e eletrônicos, 7 lojas de eletrodomésticos, 6 hipermercados, e 4 lojas de reparos de celulares. Os principais questionamentos foram sobre o descarte de resíduos de celular, com ênfase na seguinte pergunta: "qual o destino dado aos aparelhos celulares descartados?". Os entrevistados também foram questionados sobre como as empresas comunicam o descarte de celulares aos clientes e ainda sobre a existência de informações em seus sítios a respeito da existência de programas de logística reversa. Após o mapeamento dos pontos de descartes/coleta, foram feitas entrevistas com os clientes que coletam esses resíduos para posterior repasse/processamento, ou seja, inicia-se o mapeamento da próxima camada da cadeia. Assim, 3 matrizes de empresas de telefonia, 2 núcleos de resíduos eletrônicos, 4 ONG's e 2 fábricas de aparelhos celulares foram visitados e a mesma pergunta sobre o destino dado aos resíduos foi feita. $\mathrm{O}$ próximo passo foi entrevistar as empresas terceirizadas de logística e triagem, por elas representarem a próxima camada da cadeia. Depois, os questionamentos foram aplicados às empresas especializadas e certificadas em manufatura reversa, como empresas de trituração, empresas de tratamento de placas e baterias. As entrevistas foram sempre feitas a fim de estruturar o fluxo da cadeia reversa de celulares e mapear os principais atores, de montante à jusante, ou seja, as entrevistas se iniciaram no consumidor final até o último membro da cadeia reversa. Além disso, através das entrevistas foi possível compreender as relações entre clientes e fornecedores, entender as operações realizadas por cada membro e suas principais dificuldades.

Com base nesse levantamento, foi mapeada a cadeia com os principais atores (clientes de material reciclado e fornecedores de celular pós-consumo e a empresa focal), utilizando a estrutura de Lambert e Cooper (2000).

No passo 4, foram feitas entrevistas em duas empresas focais (A e B) a fim de validar os principais critérios da literatura e que eram utilizados para a decisão de descarte e ou venda dos resíduos do celular. Estas entrevistas também foram importantes para definir a importância entre os critérios e como eles são mensurados pelo decisor. Os critérios e as respectivas pesquisas que corroboram para os fatores de decisão podem ser vistos na Tabela 1.

\begin{tabular}{|c|c|c|c|}
\hline Critérios & Subcritérios & Descrição & Referência \\
\hline \multirow{4}{*}{$\begin{array}{l}\text { Aspectos } \\
\text { estratégicos }\end{array}$} & $\begin{array}{l}\text { Relacionamento com o } \\
\text { cliente }\end{array}$ & $\begin{array}{l}\text { Facilidade em negociar e } \\
\text { tomar decisões }\end{array}$ & El Faro et al (2013) \\
\hline & Volume de materiais & $\begin{array}{c}\text { Volume ocupado na } \\
\text { estocagem e transporte }\end{array}$ & $\begin{array}{c}\text { Mendonça (2013); Geyer e Blass } \\
\text { (2010) }\end{array}$ \\
\hline & Frequência de entrega & $\begin{array}{l}\text { Frequência de entrega de } \\
\text { celulares inteiro/partes }\end{array}$ & El Faro et al (2013) \\
\hline & Nível de serviço & $\begin{array}{c}\text { Qualidade do serviço de } \\
\text { entregue ao cliente }\end{array}$ & $\begin{array}{c}\text { Jayant (2014); Fernando e Jorge } \\
\text { (2015) }\end{array}$ \\
\hline \multirow{3}{*}{$\begin{array}{l}\text { Aspectos } \\
\text { econômicos }\end{array}$} & Custo de logística & $\begin{array}{l}\text { Custos de armazenagem e } \\
\text { transporte }\end{array}$ & $\begin{array}{l}\text { Geyer e Blass (2010); Ramos et } \\
\text { al (2014). }\end{array}$ \\
\hline & Custos de operação & $\begin{array}{l}\text { Salário de funcionários, } \\
\text { aluguel, energia, triagem. }\end{array}$ & $\begin{array}{l}\text { Miguez (2010); Ramos (2014); } \\
\text { Hori (2010). }\end{array}$ \\
\hline & Preço de venda & $\begin{array}{l}\text { Preço de mercado do } \\
\text { celular/partes }\end{array}$ & Fernando e Jorge (2015) \\
\hline \multirow{3}{*}{$\begin{array}{l}\text { Aspectos } \\
\text { ambientais }\end{array}$} & Poluição com transporte & $\begin{array}{l}\text { Poluição emitida pelos meios } \\
\text { de transporte }\end{array}$ & Ramos et al (2014) \\
\hline & Uso da energia & $\begin{array}{c}\text { Consumo de energia nas } \\
\text { operações e transporte }\end{array}$ & Miguez (2010) \\
\hline & $\begin{array}{l}\text { Grau de intoxicação do } \\
\text { produto }\end{array}$ & $\begin{array}{c}\text { Produtos tóxicos presentes no } \\
\text { celular }\end{array}$ & $\begin{array}{c}\text { Miguez (2010); Acosta et al } \\
\text { (2008) }\end{array}$ \\
\hline
\end{tabular}

Tabela 1: Critérios e fatores de decisão considerados pelos entrevistados. (Fonte: Elaboração própria)

Para a construção da árvore de decisão, foi utilizado o software V.i.s.a. (Belton \& Stewart, 2002). Os gerentes das empresas A e B também avaliaram qualitativamente os critérios e subcritérios, as respostas variaram entre alta, média e baixa importância para cada critério ou subcritério. Foi utilizado o método Analytic Hierarchy Process (AHP) (Saaty, 1980) para calcular os pesos (grau de importância) dos critérios. O Quadro 1 mostra a escala de valores sugerida para cálculo da prioridade relativa de cada critério. 


\begin{tabular}{|c|c|c|}
\hline $\begin{array}{l}\text { Grau de } \\
\text { importância }\end{array}$ & Significado & Explicação \\
\hline $\begin{array}{l}1 \\
2\end{array}$ & $\begin{array}{l}\text { Importância igual } \\
\text { Fraca ou leve }\end{array}$ & As duas atividades contribuem igualmente para objetivo \\
\hline 3 & Importância moderada & $\begin{array}{l}\text { Experiência e julgamento levemente em prol de uma atividade } \\
\text { em relação à outra. }\end{array}$ \\
\hline $\begin{array}{l}4 \\
5\end{array}$ & $\begin{array}{c}\text { Mais moderada } \\
\text { Grande importância }\end{array}$ & $\begin{array}{l}\text { Experiência e julgamento consideravelmente em prol de uma } \\
\text { atividade em relação à outra. }\end{array}$ \\
\hline $\begin{array}{l}6 \\
7\end{array}$ & $\begin{array}{l}\text { Forte importância } \\
\text { Muito forte }\end{array}$ & $\begin{array}{l}\text { Uma atividade é fortemente valorizada em relação à outra; } \\
\text { Posição de dominância na prática. }\end{array}$ \\
\hline $\begin{array}{l}8 \\
9\end{array}$ & $\begin{array}{l}\text { Extremamente forte } \\
\text { Importância extrema }\end{array}$ & Maior nível de diferença possível entre as atividades \\
\hline
\end{tabular}

Quadro 1: Escala do modelo AHP. Fonte: Saaty (1980).

Assim, os Gerentes A e B avaliaram os critérios par a par de acordo com o grau de importância apresentado no Quadro 1. Após o cálculo da prioridade relativa de cada critério e atendimento do índice de consistência (Saaty, 1980), esses critérios foram utilizados como peso na análise multicritério. Foi considerada a média desses valores como o peso final.

A partir da árvore de decisão, por meio do software V.I.S.A, foram avaliadas as alternativas de comercialização e análises de sensibilidade com o objetivo de auxiliar na tomada de decisão de comercialização dos resíduos de celulares para as empresas A e B.

\section{RESULTADOS E ANÁLISES}

Nos tópicos a seguir, serão apresentadas a caracterização da cadeia reversa de celulares e análise de decisão multicritérios.

\subsection{Caracterização da cadeia reversa de celulares}

Para a caracterização da cadeia reversa dos celulares, parte do levantamento sobre os principais atores foi feito a partir de entrevistas com os clientes finais, empresas compradoras, intermediárias e transportadoras dos resíduos eletrônicos. Segundo De Brito (2003) os principais atores da logística reversa são: os membros da cadeia de suprimentos direta, as instituições governamentais e os especialistas em cadeias reversas como coletores, empresas de reciclagem, fundações e organizações, cooperativa. Ou seja, de uma maneira geral a cadeia reversa de celulares é basicamente formada por esses membros que fazem o descarte do celular ou parte de seus componentes para serem reciclados. Doações são feitas por pessoas físicas e empresas que participam da cadeia de suprimentos tradicional, estes atores viabilizam os produtos, ou parte deles, e enviam à triagem; logo depois os componentes são enviados às empresas especializadas e certificadas em manufatura reversa. Após a reciclagem, os produtos são levados à produção industrial. A Figura 3 mostra este fluxo e os principais atores e níveis de gerenciamento entre os elos. 


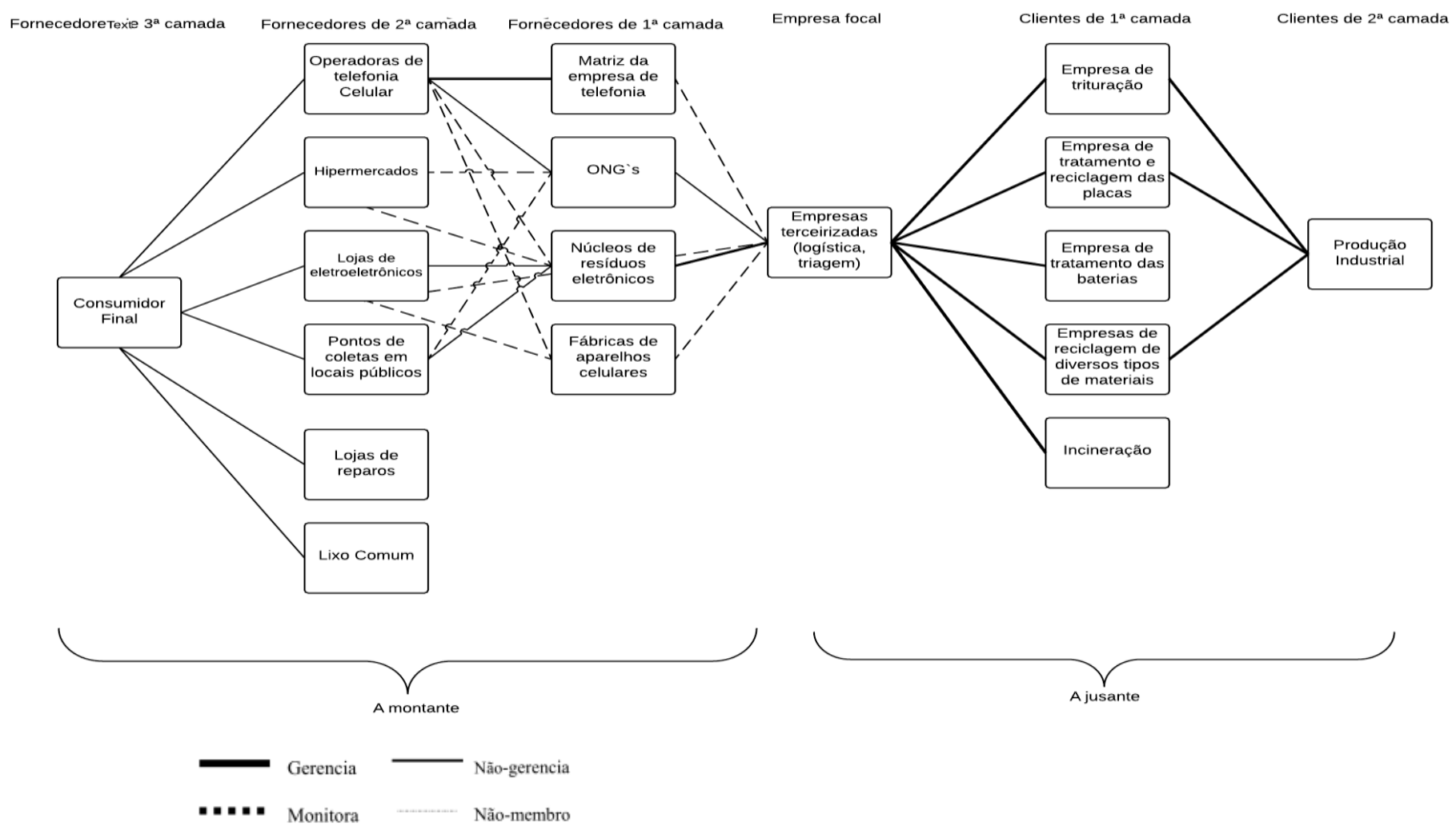

Figura 3: Cadeia de suprimentos reversa de aparelhos celulares. (Fonte: elaboração própria)

\section{Membros da cadeia}

Lambert e Cooper (2000) classificam os membros entre principais e de suporte. Os membros primários estão representados por empresas de logística, armazenamento e triagem dos eletrônicos, núcleo de resíduos eletrônicos, fábricas de aparelhos celulares, empresas de reciclagem, entre outros. Os membros de apoio estão representados pelos fornecedores de materiais diversos de almoxarifado, fornecedores de equipamentos diversos, de assistência técnica e de manutenção, entre outros.

Segundo Lambert e Cooper (2000), a empresa focal é definida a partir de fatores como: ter o maior número de fornecedores ou clientes, agregar mais valor à rede, ser responsável por vários processos dentro da cadeia, deter mais recursos financeiros, entre outros. Assim, a empresa que realiza os serviços de logística de armazenamento e triagem foi definida como empresa focal da cadeia reversa de celulares, pois ela permite que o fluxo de produtos e informações entre os elos sejam gerenciados além de concentrar a decisão de reciclagem ou não do resíduo. Quase todos os pontos de coleta enviam os resíduos para esse tipo de empresa, assim o volume que ela transporta, armazena e faz a triagem também é muito maior que o dos outros atores da cadeia. Essa empresa se situa numa posição horizontal mais próxima ao cliente final, já que a empresa focal fornece os aparelhos com parte dos processos para reciclagem já realizada.

\section{Dimensão horizontal das camadas}

A estrutura horizontal faz referência ao número de fileiras que cruzam a rede de suprimentos, pode ser longa ou curta (Lamber \& Cooper, 2000). Ela é classificada à montante e à jusante, ou seja, fornecedores e clientes, respectivamente, da empresa focal.

(A) à montante - A primeira camada é representada em grande parte por empresas que já iniciaram o processo de reciclagem, fazendo a descaracterização do aparelho celular, ou mesmo já reaproveitando parte dos aparelhos coletados como é o caso das fábricas de celulares. Outros participantes da cadeia agregam menos valor como é o caso das ONGs que apenas auxiliam nas conexões entre os elos da cadeia. A segunda camada de fornecedores é formada pelos diversos pontos de coleta de aparelhos celulares, como as operadoras de telefonia, os hipermercados, as lojas de eletrônicos e eletrodomésticos e os pontos públicos de coleta espalhados pela cidade, entre outros. Devido a essas inúmeras possibilidades de descarte do aparelho celular, a verticalização da segunda camada de fornecedores tem grande dimensão. Já a terceira camada é formada pelo consumidor final que descartam o celular já utilizado, como a pessoa física que faz o uso 
pessoal do aparelho celular, mas também empresas, comércio, entre outros que utilizam de celulares para uso profissional.

(B) à jusante - A primeira camada de clientes da empresa foco é composta pelas mais variadas empresas de reciclagem, são empresas que reciclam ou reutilizam o plástico, a borracha, o metal, ou seja, os resíduos oriundos do aparelho celular. Também fazem parte desta camada, empresas específicas de reciclagem, como as empresas que só tratam da reciclagem de metais ou da carcaça do celular. Em seguida, após a reciclagem, os materiais são destinados à produção industrial se transformando em um novo produto. Dentre os resíduos gerados pelo celular, os metais devem receber uma maior atenção, visto que são esses componentes do celular com maior valor econômico, assim, o ouro, cobre, ferro entre outros, são comercializados e em seguida utilizados na produção industrial de diversos produtos. Essa camada também é composta por empresas que fazem a incineração dos materiais que não podem ser reciclados, assim ocorre a destruição térmica dos resíduos e a sua significativa redução de volume. Após a camada composta por produção industrial, o próximo cliente é novamente o consumidor final, fechando assim o ciclo da cadeia de suprimentos.

\section{Tipos de ligações entre os elos da cadeia}

A partir da Figura 3 e respectivas análises, pode-se notar que as ligações não gerenciadas são mais comuns, principalmente no início da cadeia, visto que uma das únicas formas que os postos de coleta usam para influenciar o descarte dos aparelhos celulares é com o lançamento de produtos novos cada vez mais inovadores. Ou seja, indiretamente esses postos de coleta fazem com que o descarte de celulares ocorra. Porém, de uma maneira geral, os postos de coletas não têm muito controle e nem tentam influenciar diretamente os consumidores sobre o descarte ideal do celular já utilizado. Isto pode ser considerado uma falha do sistema reverso de eletrônicos, que não usam do marketing, por exemplo, como uma forma de mostrar aos consumidores as possibilidades de descarte do resíduo eletrônico. Segundo Dias e Teodosio (2006), este problema está relacionado ao baixo investimento em informação e tecnologia levadas aos consumidores sobre as práticas de descarte do lixo eletrônico. Oferecer ao grande público o conhecimento sobre a reciclagem e retorno dos materiais é uma medida fundamental.

As ligações monitoradas também estão presentes na cadeia, em grande parte das vezes entre os fornecedores de segunda camada e os de primeira camada. Os de primeira camada que são representados pelas organizações não governamentais, núcleo de resíduos eletrônicos, fábricas de aparelhos celulares entre outros devem manter certo monitoramento sobre os pontos de coleta, pois precisam saber a frequência que devem buscar os resíduos em tais locais, a quantidade de aparelhos usados disponíveis nestes pontos etc. Assim, a empresa focal também monitora grande parte dos seus fornecedores, pois precisa de informações de como e de quando recolher os resíduos, qual a quantidade que deverá abastecer seus estoques e fazer a triagem. Porém, segundo Leite, Lavez \& Souza (2009), ainda não existe uma integração entre os membros da cadeia diversa como hipermercados, lojas fabricantes de celular e os membros da cadeia reversa como núcleo de resíduos eletrônicos, o que, seria capaz de diminuir os custos relativos ao retorno dos materiais. Já as ligações gerenciadas são menos frequentes, visto que é difícil manter grande parte do controle entre o fluxo de produtos principalmente no início da cadeia. Essas ligações são encontradas mais no fim da cadeia reversa, onde as empresas de reciclagem mantêm um grande vínculo de colaboração com a empresa terceirizada de logística, armazenamento e triagem e também com o seu cliente final que é a produção industrial.

\subsection{Análise de decisão para comercialização dos resíduos do celular}

Uma vez mapeada a cadeia reversa de celular, esta pesquisa analisou quais aspectos interferem na comercialização do lixo eletrônico. A empresa focal é a mais indicada para este tipo de análise, uma vez que detêm o poder na cadeia (Lambert e Cooper, 2000). Portanto, duas empresas focais (A e B) foram escolhidas para o desenvolvimento do modelo de decisão de comercialização, baseado na pesquisa de Belton e Stewart (2002), por meio dos seguintes passos:

\section{Definição do problema}

O problema se refere à maneira de comercializar o lixo eletrônico. A comercialização sofre influência de muitos fatores, tais como: valor de venda da placa, valor de venda da bateria, da carcaça, do celular completo, volume de material coletado, frequência de material coletado, custo de armazenagem, modo de fazer a triagem. Desta forma, procura-se definir os principais critérios para essa comercialização. 


\section{Objetivos e critérios}

O objetivo é o primeiro passo para o processo de tomada de decisão. É necessário descrever seus três componentes: contexto da decisão, o objeto e a direção da preferência (Keeney, 1992). Dentro do contexto da decisão sobre a cadeia reversa dos resíduos eletrônicos, o objetivo fundamental é verificar o que as empresas focais dão valor no momento da comercialização dos resíduos com os seus clientes.

Os objetivos fundamentais que agregam valor à comercialização de resíduos de celular foram estabelecidos por meio de entrevistas com a empresa focal e da revisão de literatura, sob três aspectos: estratégicos, econômicos e ambientais.

Os aspectos estratégicos são representados pelo grau de colaboração entre os parceiros e eficiência na transação.. Para um maior volume e frequência de resíduos comercializado com um parceiro, espera-se maior nível de colaboração; ou seja, mais informação compartilhada, menos incerteza, mais confiança e comprometimento. Consequentemente, espera-se também um melhor nível de serviço (Bowersox, Closs, Cooper e Bowersox, 2013).. Já os aspectos econômicos consideram relevantes o preço de venda obtida na comercialização dos produtos e os custos envolvidos nas atividades desenvolvidas pela cadeia focal, que abrangem principalmente os custos de operação, transporte e armazenamento. Os aspectos ambientais envolvem a poluição causada pelos meios de transportes durante a distribuição dos materiais, o uso da energia durante as operações e a intoxicação causada pelos materiais. A Figura 4 mostra a Árvore de Valor composta pelos aspectos estratégicos, econômicos e ambientais. Esses aspectos serão denominados por critérios e para cada um desses, os respectivos subcritérios.

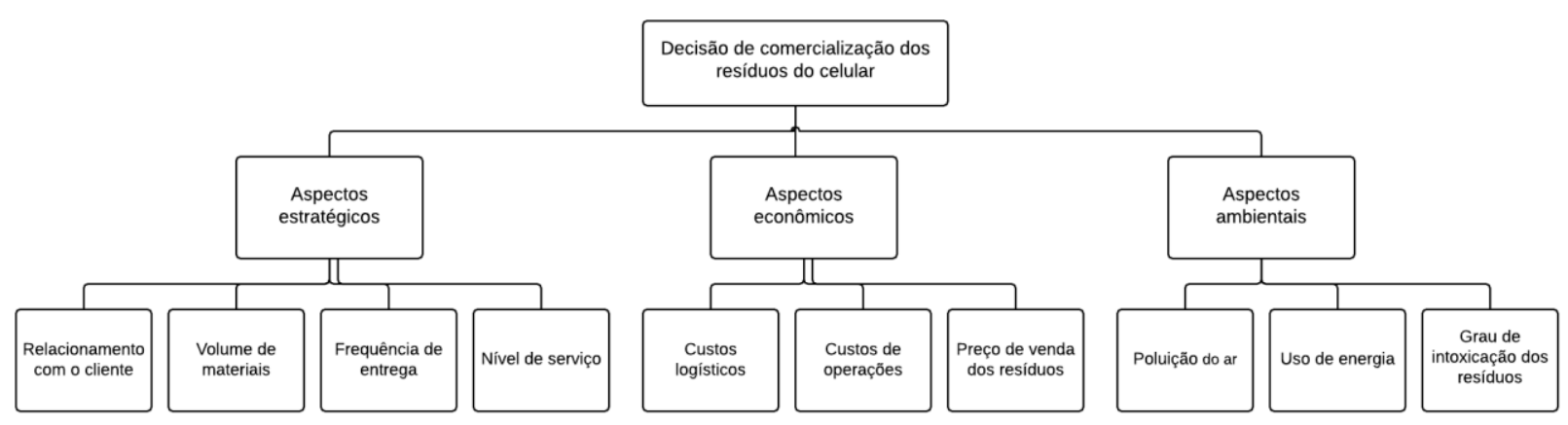

Figura 4: Árvore de valor. (Fonte: elaboração própria)

\section{Criar as alternativas}

Com o intuito de atender os objetivos foram levantadas as alternativas disponíveis no mercado baseando em entrevistas com duas empresas focais. As alternativas selecionadas foram: (a) decisões da empresa A, (b) decisões da empresa B.

\section{Caracterização das empresas focais}

\section{Empresa A}

A Empresa A foi inaugurada em 2010 por meio de uma parceria entre a Prefeitura de Sorocaba e uma cooperativa de reciclagem. Ela tem atuado no ramo de reciclagem exclusiva de materiais eletrônicos. Assim, todo o material eletrônico recolhido na cidade pela empresa é encaminhado à reciclagem, visando dar uma destinação adequada a este tipo de resíduo e a preservar o meio ambiente.

A empresa recebe qualquer tipo de resíduo eletrônico, seja diretamente por meio de pessoas físicas ou por coletas agendadas. Neste caso, existem pontos de coletas de celulares distribuídos pela cidade, nos terminais rodoviários, em algumas ONGs, escolas públicas. Após a coleta é feita a descaracterização dos celulares, ou seja, o celular é quebrado, o que inviabiliza a sua reutilização. Neste processo, é retirada a placa, a bateria e a carcaça que são as partes que interessam às empresas de reciclagem por terem maior valor de mercado. Em seguida, os materiais são enviados para serem tratados separadamente pela próxima camada da cadeia. É neste momento que o modelo de decisão pode contribuir para a escolha da melhor maneira para comercialização das partes ou do celular inteiro. 


\section{Empresa B}

A Empresa B oferece soluções de logística reversa em todo o Brasil, integrando processos de reciclagem, reaproveitamento de matérias-primas, destinação de resíduos, garantindo facilidade, maior produtividade, atendimento às legislações governamentais e oferecendo sustentabilidade da indústria ao cliente.

De forma diferente da empresa A, esta empresa trabalha de forma integrada na cadeia reversa; ou seja, é responsável por todos os processos da cadeia reversa de eletrônicos. O início dos trabalhos da empresa B já se inicia na coleta, na qual empresas e pessoas físicas encaminham os celulares pós-uso para a reinserção na cadeia. A coleta acontece de várias formas: através do e-mail da empresa o doador pode agendar uma entrega e assim a empresa busca o material; pode ser feita através dos correios, dependendo da quantidade que será doada; ou mesmo em um dos 400 pontos de coleta distribuído no país. Em seguida acontece a separação dos materiais: separar todos os componentes viável economicamente, isto é são aproveitadas as baterias, os plásticos e as placas eletrônicas. As baterias são vendidas para recicladoras nacionais. Os plásticos são reciclados e reinseridos na fabricação de produtos finais na própria empresa. No que se refere às placas, uma pequena parte dos metais também é utilizado na própria empresa e outra é exportada.

A sustentabilidade ambiental é a característica mais marcante da empresa. Todos os seus clientes devem ser homologados de acordo com pré-requisitos "verdes" estabelecidos pela empresa. O cliente deve ter processos limpos e seu produto final também deve estar de acordo com as normas ambientais exigidas. A Empresa B tem um código de conduta que a coloca como responsável pelo produto final de seu cliente e por isso ela audita toda a cadeia.

\section{Ponderação dos pesos e valoração das alternativas}

Os pesos para os critérios e subcritérios foram definidos a partir dos dois tomadores de decisão, por meio do método AHP. O modelo AHP foi utilizado para testar o nível de consistência das respostas dadas pelos decisores Também foram avaliadas pelo decisor as alternativas em relação aos subcritérios. Desta forma, o decisor atribuiu valores qualitativos para as alternativas de maneira que a função de valor refletisse as preferências em diferentes níveis de escala. A Tabela 2 apresenta a importância atribuída por cada decisor da empresa A e B para os subcritérios.

\begin{tabular}{|l|l|l|}
\hline Subcritérios & Empresa A & Empresa B \\
\hline Relacionamento com o cliente & Média importância & Média importância \\
\hline Volume de material & Média importância & Baixa importância \\
\hline Frequência de entrega & Média importância & Baixa importância \\
\hline Nível de serviço & Média importância & Média importância \\
\hline Custos de logística & Alta importância & Média importância \\
\hline Custos operacionais & Média importância & Média importância \\
\hline Preço de venda & Alta importância & Média importância \\
\hline Poluição & Baixa importância & Alta importância \\
\hline Consumo de energia & Média importância & Alta importância \\
\hline Grau de intoxicação & Média importância & Alta importância \\
\hline
\end{tabular}

TABELA 2: Resumo descritivo dos critérios e alternativas. (Fonte: Elaboração própria)

\section{Aplicação e análise do modelo no software V.I.S.A.}

A partir da representação do problema, por meio da árvore de decisão, da ponderação dos pesos dos critérios da decisão e da valoração das alternativas, construiu-se o modelo de decisão de comercialização do celular. Os resultados mostram a importância dada por cada decisor aos aspectos estratégicos, econômicos e ambientais. Cada critério é a média dos resultados das respostas das duas empresas envolvidas no estudo de caso. O modelo encontrou os valores preferenciais de $34,8 \%, 32,7 \%$ e $32,5 \%$ para esses critérios, respectivamente. Vale ressaltar que as empresas A e B apontam, dentro dos aspectos estratégicos, um maior volume de resíduos elevaria a empresa à excelência na comercialização. Já os aspectos econômicos são influenciados pelos custos e pelo preço de venda dos resíduos. No que tange os aspectos ambientais, sua alta porcentagem é explicada devido às empresas voltadas para reciclagem de resíduos de celulares terem a responsabilidade ambiental e trabalharem justamente com a finalidade de mitigarem esses problemas. Além disso, a implementação do Pnrs e os próprios consumidores têm pressionado as empresas a adquirirem hábitos mais "verdes". Para Leite, Lavez \& Souza (2009) os aspectos estratégicos de gerenciamento de 
suprimentos são primordiais para os programas de logística reversa. Como por exemplo no caso do volume, que gera estoques e consequentemente custos, o que implica na adoção de uma política de estoques adequada. Já o direcionador econômico também é um dos aspectos principais para a implementação de um programa de logística reversa, as empresas precisam realizar estudos acerca dos ganhos que terão com este tipo de iniciativa para confirmar sua viabilidade. Em relação à importância dada aos aspectos ambientais, algumas medidas como a realização de processos de reciclagem, redução da poluição e diminuição do gasto de energia, certamente contribuem para a melhoria a imagem da empresa no mercado..

A Figura 5 mostra os resultados de cada critério e respectivos subcritérios. Verifica-se que para os critério estratégico, o relacionamento com o cliente e o nível de serviço são os subcritérios mais importantes para os decisores, enquanto o volume de material e a frequência de entrega são menos relevantes, pois geralmente espera-se que as empresas tenham um volume mínimo para fazer a entrega para seus clientes. Porém, de acordo com Rodrigues, Rodrigues, Leal e Pizzolato (2002) apesar de ser considerado um fator importante, o relacionamento entre os elos da cadeia reversa de celulares está longe de atingir o nível de eficiência necessária. A falta de coordenação e colaboração nos processos de coleta, manuseio, armazenagem, processamento e troca de materiais recicláveis são considerados como grandes barreiras à logística reversa. Esta falta colaboração na cadeia talvez dificulta o gerenciamento do controle de estoques e manuseio de grandes volumes como ponto primordial para se obter economias de escala.

Para os aspectos econômicos, os três subcritérios têm importância aproximadamente iguais para os decisores, sendo os "custos de operação" o subcritério de maior pontuação. Esta alta porcentagem nos custos de operação pode ser explicada devido à alta importância dada pela empresa $\mathrm{B}$, o que representa a maior parte dos custos da empresa, envolvendo os custos com funcionários que fazem a coleta, custos com funcionários que fazem a descaracterização do material, custo do aluguel, custo das máquinas que fazem o processo industrial reverso, entre outros. Segundo Franke, Basdere, Ciupek e Liger (2006) esses custos se referem a custos de operação, ou seja, de desmontagem, que pode ser feito de forma manual ou mecanizada com uso de robôs, custo de triagem, reprocessamento e inspeção.

Já no que se refere aos aspectos ambientais, o "grau de intoxicação dos resíduos" é o subcritério com maior importância, devido à preocupação com os funcionários que trabalham com tais produtos e também com o consumidor final. Segundo Pires (2007) existe uma pressão às empresas fabricantes para a substituição de matérias-primas por outros materiais menos tóxicos, na busca de constituição de produtos mais sustentáveis.

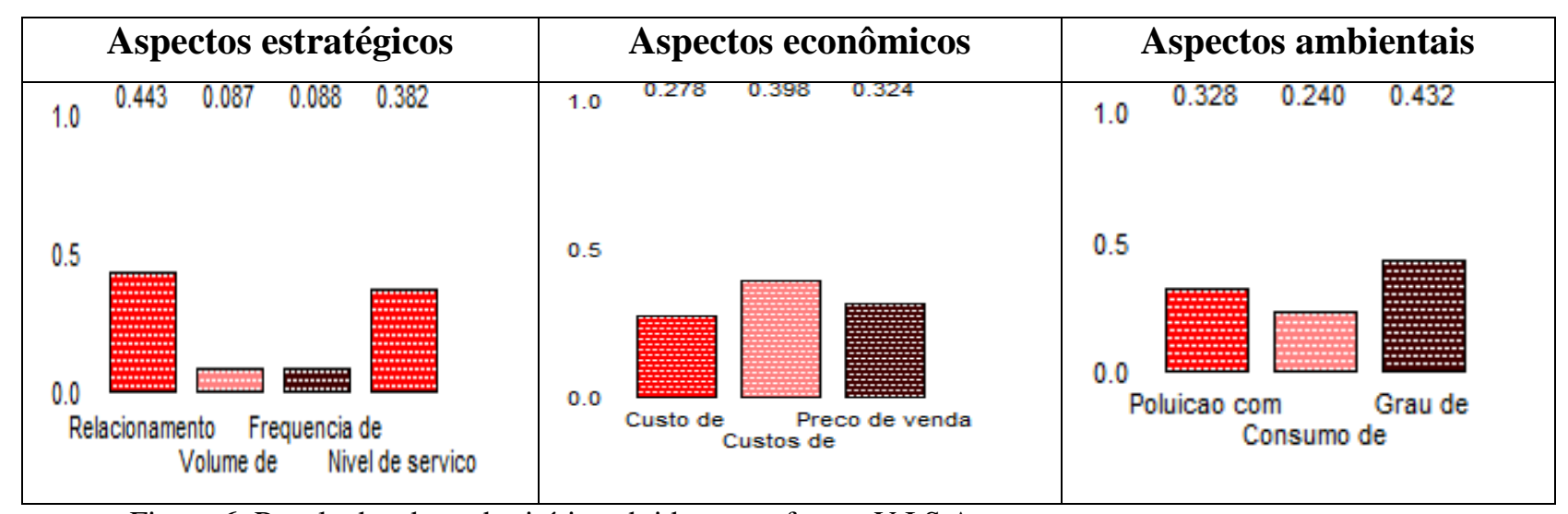

Figura 6: Resultados dos subcritérios obtidos no software V.I.S.A

Fonte: elaboração própria

Alternativa escolhida a partir da modelagem no software V.I.S.A.

Ao analisar os resultados, o modelo considerou as preferências da empresa A tão relevantes quanto às preferências da empresa B, sugerindo um empate, como mostra a Figura 6. 


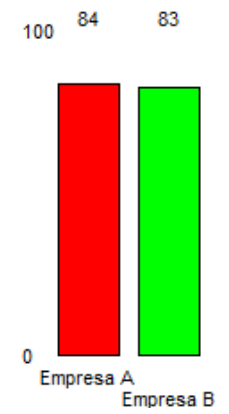

Figura 6: Resultados obtidos a partir da modelagem no software V.I.S.A

Fonte: elaboração própria.

Os resultados mostram que a maneira de comercialização dos resíduos deve ser feita dependendo do foco que a empresa envolvida deseja adotar, pois o estudo trata de duas empresas com focos distintos. Para o caso da empresa $\mathrm{A}$, os aspectos estratégicos e econômicos são mais relevantes por ser uma empresa com foco na venda dos resíduos, ou seja, dá maior importância ao volume, frequência, custos de logística e preço de venda dos resíduos do que a Empresa B. Dessa forma, a Empresa A foca no volume e na frequência, o que evidencia sua característica de empresa mais oportunista do que colaborativa e eleva o seu patamar de importância referente aos aspectos estratégicos e, por estar próxima ao mercado, visa o maior número de vendas. Ou seja, esses subcritérios são de suma importância no relacionamento com o cliente direto e traz economia de escala (através do volume), fato que mostra a relevância dos aspectos econômicos. No entanto, para a empresa $\mathrm{B}$, os aspectos ambientais são mais importantes por se tratar de uma empresa com valores voltados à sustentabilidade ambiental e por participar de todos os processos da cadeia reversa. Isto quer dizer que a empresa B procura melhorar os níveis de poluição gerada em seus processos, de consumo de energia e melhorar o grau de intoxicação gerados pelos resíduos eletrônicos, o que pode causar danos irreversíveis à saúde dos consumidores e pessoas que trabalham com tais resíduos. Segundo Hagelaar e van der Vorst (2001), à medida que aumenta o comprometimento da estratégia da cadeia de suprimento com a sustentabilidade ambiental, é necessária uma estrutura mais complexa de relacionamento entre as empresas, principalmente em relação às funções que são compartilhadas e ao maior número de consultas entre os membros da cadeia de suprimento. Assim houve uma compensação nos resultados, gerando um empate no resultado final (vide Figura 7).

\begin{tabular}{|c|c|c|}
\hline Aspectos estratégicos & Aspectos econômicos & Aspectos ambientais \\
\hline $100+71$ Empresa B & $\begin{array}{l}100 \quad-92 \text { Empresa A } \\
t-80 \text { Empresa B }\end{array}$ & $100[-100$ Empresa B \\
\hline $\begin{array}{l}0 \\
0\end{array}$ & $0 \quad 1$ & $\begin{array}{ll}0 & 1 \\
& \text { Units }\end{array}$ \\
\hline
\end{tabular}

Figura 7: Resultados por critério obtidos a partir da modelagem no software V.I.S.A

Fonte: elaboração própria.

Esses resultados também mostram que a Empresa focal A parece assumir a posição de empresa mais a jusante na cadeia reversa, pois se espera que tenha ligações mais gerenciáveis com empresas que tem um foco econômico maior, ou seja, buscam o lucro independente dos danos ambientais. Isso é comprovado através das entrevistas feitas com o gestor da empresa A, que mostrou dar uma alta importância aos custos gerados pelos processos reversos. Além disso, até mesmo quando se tratava dos aspectos não econômicos (estratégicos e ambientais), o gestor mostrou se preocupar com a parte financeira, como, por exemplo, ao 
perguntar sobre o subcritério "consumo de energia", ele relacionou este critério ao custo com o alto consumo de energia e não com os problemas ambientais.

Por outro lado, a Empresa B dá mais importância para os aspectos ambientais, o que explica sua posição como empresa focal, pois como esta empresa faz todo o processo reverso, a sua responsabilidade ambiental e sua preocupação em ter um produto final "verde" é de extrema importância. Alguns aspectos estratégicos, tais como o relacionamento e o nível de serviço, também são bem gerenciados pela Empresa B, já que há um gerenciamento dos elos de montante a jusante e devido à grande preocupação da empresa com os códigos de conduta de seus parceiros e com o consumidor final. Segundo o gerente da empresa, somente após todo o processo de análise dos aspectos ambientais e dos parceiros é feita a negociação de preços e levados em conta os custos da empresa. Conforme citado por Alves Filho, Cerra, Maia, Sacomano Neto e Bonadio (2004), a busca por relacionamentos estáveis por parte da empresa focal ocorre em razão da sua impossibilidade de exercer controle sobre toda a cadeia de suprimentos, desde a fonte de matéria-prima até o ponto de consumo final. Assim, para que haja vantagem competitiva em determinados elos da cadeia, é necessário que os relacionamentos de longo prazo sejam pautados por cooperação e parceria, e não pela competição.

\section{CONSIDERAÇÕES FINAIS}

De acordo com os objetivos da pesquisa, foi feita a caracterização da cadeia de logística reversa de aparelhos celulares. Por meio do modelo de Lambert e Cooper (2000), foram explicitados os participantes que compõem essa cadeia, as formas de gerenciamento existentes entre os elos principais e as dimensões horizontal e vertical da cadeia. Além disso, foi proposto um modelo de análise de decisão para auxiliar a empresa focal, aquela que detém maior conhecimento da cadeia, na tomada de decisão para comercialização dos resíduos do celular.

Conclui-se que é preciso ter um relacionamento mais efetivo principalmente entre os membros a montante da cadeia, onde estão localizados os pontos de coletas que não utilizam eficientemente as estratégias de marketing para comunicar aos consumidores sobre a necessidade da devolução dos aparelhos nos devidos pontos de coleta. Segundo Leite, Lavez e Souza (2009), outro ponto relevante é que as discussões entre os maiores interessados sobre o tema, tais como fabricantes, recicladores, coletores, legisladores e sociedade, ainda são incipientes, e que o debate entre todos os atores das cadeias sustentáveis traria evoluções consideráveis para o desenvolvimento do setor.

O público-alvo desta pesquisa são gerentes que sejam tomadores de decisões em empresas principalmente de cadeias reversas. A utilização deste trabalho por este público pode ser útil como referência para entender como se dão as relações nos diversos elos e para que os tomadores de decisão possam desenvolver uma decisão estruturada com base nas suas preferências e auxiliar na comercialização de resíduos na cadeia reversa

Algumas limitações foram notadas durante a execução da pesquisa, sendo elas: falta de informações por parte dos funcionários das empresas sobre os programas de logística reversa; dificuldade em acessar dados quantitativos das empresas envolvidas; dificuldade do decisor em julgar pesos para os critérios da tomada de decisão, entre outros.

Para trabalhos futuros, propõe-se estudo dos elos a jusante da cadeia, principalmente da produção industrial que representa a última etapa da cadeia reversa dos celulares, ou seja, quando os componentes dos celulares voltarão à cadeia num novo ciclo e talvez fazendo parte de outro produto.

\section{Agradecimento: Este estudo teve suporte financeiro do CNPq (Processo 485080/2013-3).}

\section{Referências}

Abinee - Associação Brasileira da Indústria de Eletroeletrônico (2015) Recuperado em maio de 2015, de: http://www.abinee.org.br/.

Achillas, C., Vlachokostas, C., Aidonis, D., Moussiopoulos, N., Iakovou, E., \& Banias, G. (2010) Optimising reverse logistics network to support policy-making in the case of Electrical and Electronic Equipment. Waste Management, 30(12), 2592-2600.

Acosta, B., Wegner, D., \& Padula, A. D. (2008) Logística reversa como mecanismo para redução do impacto ambiental originado pelo lixo informático. Recadm, 7(1), 1-12.

Revista de Gestão Social e Ambiental - RGSA, São Paulo, v. 10, n. 2, p. 53-69, maio/ago. 2016. 
Alves Filho, A. G., Cerra, A. L., Maia, J. L., Sacomano Neto, M., \& Bonadio, P. V. G. (2004) Pressupostos da gestão da cadeia de suprimentos: evidências de estudos sobre a indústria automobilística. Gestão \& Produção, 11(3), 275-288.

Araujo, A. C. D., Matsuoka, É. M., Ung, J. E., Hilsdorf, W. D. C., \& Sampaio, M. (2013) Reverse logistics in the e-commerce: a case study. Gestão \& Produção, 20(2), 303-320.

Barrat, M. (2004) Understanding the meaning of collaboration in the supply chain. Supply Chain Management: An International Journal, 9, 30-42.

Besen, G. R., Günther, W. M. R., Rodriguez, A., \& Brasil, A. L. (2010) Resíduos sólidos: vulnerabilidades e perspectivas. Saldiva P. et al. Meio ambiente e saúde: o desafio das metrópoles. São Paulo: Ex Libris.

Belton, V., \& Stewart, T. (2002) Multiple criteria decision analysis: an integrated approach. Springer Science \& Business Media.

Betts, K. (2008) Producing usable materials from e-waste. Environ. Sci. Technol, 42(18), 6782-6783.

Bowersox, D. J., Closs, D. J., Cooper, M. B., \& Bowersox, J. C. (2013) Gestão logística da cadeia de suprimentos. AMGH Editora.

Caldwell, B. (1999) Recuperado em julho de 2016, de://www. informationweek. com/729/logistics. htm.

Corsten, D., \& Felde, J. (2005) Exploring the performance effects of key-supplier collaboration.

International Journal of Physical Distribution, 35(6), 445- 461.

Daher, C. E., Silva, E. P. D. L. S., \& Fonseca, A. P. (2006) Logística reversa: oportunidade para redução de custos através do gerenciamento da cadeia integrada de valor.

Demajorovic, J., Huertas, M. K. Z., Boueres, J. A., da Silva, A. G., \& Sotano, A. S. (2012) Logística reversa: como as empresas comunicam o descarte de baterias e celulares?/reverse logistics: how do companies report the disposal of batteries and cell phones?/logística reversa: ¿ cómo las empresas comunican el descarte de bater ías y celulares? Revista de Administração de Empresas, 52(2), 165.

De Brito, M. P. (2003) Management reverse logistics or reversing logistics management. Erasmus Research Institute of Management (ERIM).

El-Ansary, A.I. (1992) A strategic perspective of communication and information systems in marketing channels. Journal of Marketing Channels, 1(4), 3- 16.

El Faro, O., Calia, R. C., \& Pavan, V. H. G. (2013) A logística reversa do lixo tecnológico: um estudo sobre a coleta do e-lixo em uma importante universidade brasileira. Revista de Gestão Social e Ambiental, 6(3), 142-153.

Ellram, L.M., \& Cooper, M.C. (1990) Supply chain management, partnership, and the shipper - third party relationship. The International Journal of Logistics Management, 1(2), 1-10.

Fernando, A. S., \& Jorge, M. (2015) Cost assessment and benefits of using RFID in reverse logistics of waste electrical \& electronic equipment (Weee). Procedia Computer Science, 55, 688-697.

Flynn, B.B., Huo, B., \& Zhao, X. (2010) The impact of supply chain integration on performance: a contingency and configuration approach. Journal of Operations Management, 28, 58-71.

Fleury, A. C., Fleury, M. T.(2004) Alinhando estratégia e competência. In: Bertero, Carlos Osmar. Gestão empresarial: estratégias organizacionais. São Paulo: Atlas.

Franke, C., Basdere, B., Ciupek, M., \& Seliger, S. (2006) Remanufacturing of mobile phones-capacity, program and facility adaptation planning. Omega, 34(6), 562-570.

Geyer, R., \& Blass, V. D. (2010) The economics of cell phone reuse and recycling. The International Journal of Advanced Manufacturing Technology, 47(5-8), 515-525.

Guarnieri, P. (2011) Logística reversa: em busca do equilíbrio econômico e ambiental. Patricia Guarnieri.

Hagelaar, G. J., \& Van der Vorst, J. G. (2001) Environmental supply chain management: using life cycle assessment to structure supply chains. The International Food and Agribusiness Management Review, 4(4), 399-412. 
Heide, J.B., \& John, G. (1990) Alliances in industrial purchasing: the determinants of joint action in buyersupplier relationship. Journal of Marketing Research, 27, 24-36

Hori, M. (2010) Custos da logística reversa de pós-consumo: um estudo de caso dos aparelhos e das baterias de telefonia celular descartados pelos consumidores (Doctoral dissertation, Universidade de São Paulo).

Jayant, A., Gupta, P., Garg, S. K., \& Khan, M. (2014) Topsis-AHP based approach for selection of reverse logistics service provider: a case study of mobile phone industry. Procedia Engineering, 97, 2147-2156.

Keeney, R. L. (1992) Value-focused thinking: a path to creative decision analysis.

Lambert, D. M., \& Cooper, M. C. (2000) Issues in supply chain management. Industrial marketing management, 29(1), 65-83.

Leite, P. R., Lavez, N., \& Souza, V. M. (2009) Fatores da logística reversa que influem no reaproveitamento do "lixo eletrônico"-um estudo no setor de informática. Simpo I.

Miguez, E. C. (2010) Logística reversa como solução para o problema do lixo eletrônico: benefícios ambientais e financeiros. Rio de Janeiro: Qualitymark.

Moraes, D.G.S., Rocha,T.B., Edwald, M.R., Pimentel, M.B.C., Silva, J.R.A. (2012) Logística reversa de celulares: avaliação de cenários. Production, 24(4), 735-741, oct./dec.

Novaes, A. G. (2001) Logística e gerenciamento da cadeia de distribuição: estratégia. operação e avaliação. Rio de Janeiro: Editora Campus.

Pires, N. (2007) Modelo para a logística reversa dos bens de pós-consumo em um ambiente de cadeia de suprimentos.

Prahinski, C., \& Kocabasoglu, C. (2006) Empirical research opportunities in reverse supply chains. Omega, 34(6), 519-532.

Ramos, T. R. P., Gomes, M. I., \& Barbosa-Póvoa, A. P. (2014) Planning a sustainable reverse logistics system: Balancing costs with environmental and social concerns. Omega, 48, 60-74.

Rodrigues, D. F., Rodrigues, G. G., Leal, J. E., \& Pizzolato, N. D. (2002) Logística reversa-conceitos e componentes do sistema. Curitiba: Encontro Nacional de Engenharia de Produção, 22.

Rogers, D. S., Tibben-Lembke, R.(2001) An examination of reverse logistics practices. Journal of Business Logistics, 22(2), 129-148.

Ruas, R., Antonello, C. S., \& Boff, L. H. (2005) Os novos horizontes de gestão: aprendizagem organizacional e competências. Bookman Editora.

Sergi, T. M. (2014) Resíduos eletroeletrônicos e seu descarte: um estudo baseado na visão dos consumidores sobre a logística reversa de computadores e celulares.

Vieira, J.G.V, Lustosa, L. J., \& Yoshizaki, H. Y. (2003) Análise da cadeia de suprimentos da indústria de laticínio da Zona da Mata Mineira: integração das empresas. Revista Pesquisa e Desenvolvimento Engenharia de Produção, (1), 30-46.

Whipple, J.M., Frankel, R., \& Daugherty, P. J. (2002) Information support for alliances: performance implications. Journal of Business Logistics, 23(2), 67-82.

Data da submissão: 13/01/2016

Data da publicação: 30/04/2016 